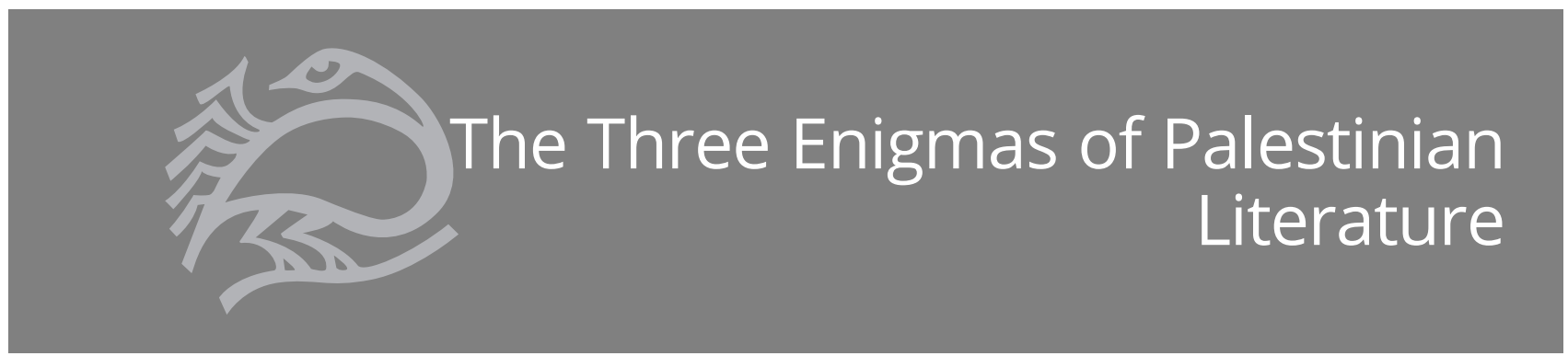

\title{
REFQA ABU-REMAILEH
}

As an introduction to the Journal's literary feature, this contribution aims to shed light on recent scholarship on Palestinian literature with a view to integrating discussions of literature more concretely within the broader field of Palestine studies. The contribution structures the discussion of the articles by Amal Eqeiq and Nora Parr around three enigmas that preoccupy scholars of Palestinian literature: writing a national literature without a nation-state, writing silence and nonlinearity, and writing fragmentation and wholeness. It highlights that challenges for scholarship on Palestinian literature revolve around rethinking conventional categorizations, canonizations, and periodizations to better understand how a national literature emerged in a context of exile, fragmentation, and statelessness, and how processes of cultural production operate in extranational conditions.

Three EnIgMAS HaUnT MANY OF US working on Palestinian literature: writing a national literature without a nation-state, writing silence and nonlinearity, and writing fragmentation and wholeness. These enigmas point to a paradox —of being something and its opposite at the same time-that lies at the heart of Palestinian literature. Palestinian literature's reality of geographical dispersion, exile, convoluted history, and unconventional development across many different countries and continents has been little studied. The desire for a nation-state and the need to fit into predetermined molds of modern Arabic literature have often distracted scholarship from honing in on what makes the more than seventy-year trajectory of Palestinian literature unique. The history of Palestinian literature as a literature of exiles and refugees, and a refugee diasporic literature itself, is becoming ever more pertinent to understanding cultural production beyond conventional national structures, boundaries, and institutions.

Palestinian literature from 1948 to the present has been studied in terms of its themes (homeland, exile, loss, gender); genres (poetry, novel, short story); relationship to politics and ideology (resistance); different periods (after the Nakba, after the 1967 war, First and Second Intifada, postOslo era); and different geographical locations (the West Bank and Gaza, 1948 Palestine, the diaspora). The Palestinian literary canon that emerges from this body of work remains eclectic. Some of the names associated with it-Jabra Ibrahim Jabra, Ghassan Kanafani, Emile Habibi, Mahmoud Darwish, Sahar Khalifeh-are very likely not to have ever met, lived in the same

Journal of Palestine Studies Vol. XLVIII, No. 3 (Spring 2019), p. 21, ISSN: 0377-919X; electronic ISSN: 1533-8614. @ 2019 by the Institute for Palestine Studies. All rights reserved. Please direct all requests for permission to photocopy or reproduce article content through the University of California Press's Reprints and Permissions web page, http://www.ucpress.edu/journals.php?p=reprints. DOI: https://doi.org/10.1525/jps.2019.48.3.21. 
country, or worked in the same political or cultural context. Even more difficult to grasp is the "bigger picture" of Palestinian literature, in other words, how to connect the dots between the hundreds of Palestinian writers and poets writing from different locations across the Arab world, Europe, North and South America, and beyond. Ultimately, some of the challenges for scholarship on Palestinian literature revolve around rethinking conventional categorizations, canonizations, and periodizations. Rereading Palestinian literary history with these questions in mind can shed light on how this "national" literature emerged in its unusual dispersed, transnational, and global fashion, and give insight into extranational processes of cultural production pertaining to a refugee and exilic nation.

The literary feature in this volume aims to introduce and give insight into new scholarship engaging with the questions, challenges, and enigmas at the heart of Palestinian literature. The articles by Amal Eqeiq, "From Haifa to Ramallah (and Back): New/Old Palestinian Literary Topography" and Nora Parr, "Ibrahim Nasrallah's Palestine Comedies: Liberating the Nation Form," offer a fascinating treatment of long-standing controversial practices such as map making, border drawing, and name giving in the context of an ever-shrinking physical Palestine. Parr focuses on the works of Ibrahim Nasrallah, a Palestinian refugee who grew up in Jordan, while Eqeiq turns her attention to the works of two Palestinian citizens of Israel, Adania Shibli and Ibtisam Azem. Through their analysis of these works, Eqeiq and Parr offer overlapping insights, but also differing visions, of temporality, geography, and nation.

The two articles initially emerged out of a conference panel devoted to the subject of space, place, and time in Palestinian literature that brought together the small and dispersed younger generation of scholars working in this field. It is hoped that this literary feature can act as a launchpad to integrate discussions of literature more concretely within the broader field of Palestine studies. While many of the questions treated in Eqeiq and Parr's articles can appear in different guises across the various disciplines of Palestine studies, this literary feature seeks to open a small window to the crucial debates on these very issues within contemporary Palestinian literature. Palestinian literature is often branded as the informal archive, memory, and history of the nation in the absence of the nation-state. This triple responsibility is important, but it endows literature with a museum-like preservation quality, turning it into something that is to be dusted off and displayed when and as needed. The present literary cluster aims to begin to address the pertinence of literature as a living creature shaping the discussions that preoccupy the field; it also aims to capture and reflect the paradoxical experiences Palestinians are grappling with more broadly.

\section{Writing a National Literature without a Nation-State}

Who gets to write the Palestinian novel? Someone inside, outside, in Ramallah, or Haifa? Or everywhere all at once? Parsing the metanarrative structures emerging from the nine novels that make up Ibrahim Nasrallah's Al-milhat al-filastiniyya (The Palestine Comedies), Parr argues that Nasrallah's work provides a missing paradigm for writing and reading the nation outside conventions. Borrowing from Walter Benjamin, Parr shows how the notion of a "constellation" expands the limits of the novel genre and opens up a space for a multiplicity of structures that helps decolonize the nation form. What she calls the "nation constellation" allows alternative 
frameworks for the nation to emerge, ones that are all-inclusive, nonlinear, noncontiguous, and openended-capable of remapping the relationships between Palestinian people and spaces. The relevance of the constellation form to the Palestinian story, Parr suggests, is that unlike the "imagined community" as a possibility that crystallized around the nation-state, it is able to pick up on, contain, and make apparent once-invisible structures.

On the flip side of flexible, generous structures that can contain a boundless Palestine, there is the lived reality of estrangement because of uprootedness inside Palestine. The figure of the alienated Palestinian in Palestine emerges out of Eqeiq's analysis of border crossing in Shibli's novella, Masas (which has been translated to English as Touch) and short stories ("May God Keep Love in a Cool and Dry Place" and "The Fence"), and Azem's novel Sariq al-nawm: Gharib Hifawi (The Sleep Thief). The city (Haifa, Jerusalem, Jaffa/Tel Aviv) becomes the site that exposes the clash between the national imaginary and the colonial present, revealing what it means to move across a fragmented geography of Palestine.

Nevertheless, there is one particular route that offers hope, according to Eqeiq. Despite multiple physical closures and reopenings since 1948, the Haifa-Ramallah route has more recently offered a subversive cultural and literary path that transcends political and national fragmentation, mapping a new horizon for decolonization. The "re-Palestinization" of urban space, argues Eqeiq, happens through self-reflection and an awareness of exclusion and alienation. In that sense, writing the invisibility of the Palestinian in the colonial reality can also be part of the constellation structure that includes not only what is imagined, but also that which is not visible.

\section{Writing Silence and Nonlinearity}

Writing silence does not mean writing without words or language, but rather finding a way to navigate the realms of the unsaid and the unspeakable. To do so invites a nonlinearity of narrative that can capture the physical, emotional, psychological, temporal, and geographical dislocation and alienation of the Palestinian subject. Knitting together narratives capable of exposing invisibility and silence also entails transcending chronology, linearity, contiguity, borders, plot, style, and genre. Both Parr and Eqeiq show us how these "negative spaces" of the Palestinian story come alive through the different narrative strategies of Nasrallah, Shibli, and Azem.

In the process of exposing invisibility and silence, the role of the reader becomes paramount. Inviting the reader into the text means laying bare the mechanics of meaning creation and narrative making. This "open," self-reflexive process is the precise opposite of the "closed," ideologically based/bound national mythmaking narrative or "architext," as Parr refers to it. Building and expanding on Gérard Genette's notion of genre structures, Parr's analysis illustrates how the architext becomes a structure of power that has the ability to single-handedly and unilaterally erase what does not fit into its frame. In this way, the architext generates a different contract with the reader, one of imposition of narrative rather than participation in narrative. On the other hand, Parr illustrates how Nasrallah's novel, Tifl al-mimhat (Eraser Child), allows one to "read power into" the nation constellation, recognize the limits of genre, and to question form and text. Parr shows us how the reader begins to see the invisibles, which are manifested in 
the space between what the protagonist witnesses (the destruction of Palestine) and what he thinks and reads (the imminent victories of the Arab armies). Ultimately the reader becomes aware of how official meaning is imposed through selective association, erasing the reality of the lived experience.

Writing silence also exposes the politics of silencing. Eqeiq highlights the vignettes in Azem's Sariq al-nawm where the protagonist, Gharib (which means stranger), experiences first-hand cultural appropriation, erasure of Palestinian memory, physical destruction of the landscape, and the disappearance of his own personal memories along with it. Despite coming from Haifa, a city historically known to welcome strangers, Gharib renounces the weight of his name and seeks the lightness of being in a dew drop, claiming a new name-Nada (which means dew). In Shibli's Touch, the protagonist, a little girl, is trying to learn language, but her attempts are fraught with hurdles of articulation and connection: hearing language fragments on the news, she cannot comprehend or pronounce "Sabra and Shatila"; in another scene, her teacher asks a classmate to either erase the word "Palestine" or throw away the ruler inscribed with the taboo word. Referring to Shibli's choice for the titles of the five vignettes that make up Touch-"Colors," "Silence," "Movement," "Language," and "The Wall"-Eqeiq shows us how alienation from language becomes a form of silence that can be written.

\section{Writing Fragmentation and Wholeness}

What brings the different vignettes, strands, and fragments together into the constellation or metanarrative whole? Parr and Eqeiq draw our attention to four possible elements: intertextuality, al-muthanna (the dual), Palestine, and decolonization.

Intertextuality and the referencing of Palestinian literary heritage create the possibility for texts to live within other texts, even if they are not physically housed in the same national space, time, or place. The nation, according to Parr, can be constituted through intertextuality to create a newly imagined vocabulary of connected fragments. In this way, Nasrallah's Palestine Comedies can imagine a nation that includes all of Palestine's noncontiguous times, spaces, and places. Eqeiq further stresses how intertextuality creates a Palestinian memory. The intertextual references in Azem's Sariq al-nawm draw a Palestinian genealogy of alienation and estrangement that connects Gharib to Saeed the Pessoptimist, the character from Emile Habibi's famous 1974 novel, and to Return to Haifa, Ghassan Kanafani's 1969 novella. This allows a "re-Palestinization" of the conceptual, historical, and literary maps that are drawn through these connections.

In Nasrallah's A 'ras amna (which has been translated into English as Gaza Weddings), Parr draws our attention to the twin paradigm as a way of understanding the links between disconnected spaces. The form of the dual (al-muthanna)-unique to the grammar of the Arabic language- has been used as a literary trope throughout the history of Arabic literature from pre-Islamic poetry to more recently in volume 1 of Elias Khoury's Children of the Ghetto trilogy (2017). The device of the double in Nasrallah's work is pictured as identical twins who resemble a split "ful bean" and the "riwayatain" (two novels) that make up the story. The twins reveal the possibility of being linked "outside bounded space and linear time" 
and the possibility of "simultaneous distinctiveness and joint wholeness," as Parr puts it. Ultimately, Parr suggests that this shows us a Palestine "imagined as a networked totality."

Palestine acts as the invisible paratext that connects the fragments. Despite the fact that there are no direct connections between the novels in The Palestine Comedies series (no recurring characters, no similar settings or periods, no connected plots, no timeline, no chronological order), Parr suggests that the shared topic of Palestine allows the individual novels to sit together as a "whole"-a seriesin-constellation. Eqeiq's analysis also reveals how an invisibly present paratextual Palestine haunts the narratives of Shibli and Azem, releasing the narrative potential of alienation.

Ultimately, the innovative, unconventional, and nonlinear narratives that Eqeiq and Parr present us with provide a platform for reading decolonization in literary narratives and storytelling. "Re-Palestinizing" Palestine involves writing the unspoken, making apparent the invisible in the colonial reality, and creating a constellation. Such transgressive and subversive strategies to decolonize Palestine emerge as essential tools to tackle the enigmas occupying the heart of Palestinian literature.

\section{About the Author}

Refqa Abu-Remaileh is an assistant professor at the Freie Universität Berlin's Arabic department where she leads the European Research Council literature project PaIREAD. 